Estudios sobre armas antiguas, arte militar $\mathrm{y}$ vida cultural en oriente y occidente XXXV (2015), pp. 61-76

ISSN: 0436-029X

doi: 10.3989/gladius.2015.0004

\title{
LOS EFECTIVOS DEL ÚLTIMO EJÉRCITO DE LA PERSIA SASÁNIDA (572-642). UNA SOLUCIÓN DESDE LAS FUENTES
}

\author{
LAST ARMY SOLDIERS OF SASSANID PERSIA (572-642)
}

POR

José Soto CHICA*

\section{Resumen - Abstract}

La cuestión del número de efectivos con que contaron los ejércitos sasánidas de los siglos VI y VII ha recibido diferentes respuestas. Respuestas que, paradójicamente, no han tenido en cuenta las precisas y múltiples informaciones que al respecto proporcionan las fuentes del periodo. Por nuestra parte y en este trabajo, abordamos dicha cuestión teniendo en cuenta la totalidad de las fuentes, ya sean estas bizantinas, orientales, persas o persoislámicas y tratamos de mostrar que el atento estudio de los datos y su confrontación crítica, permite evaluar con suma precisión el poderío militar de la Persia sasánida y establecer así una base comparativa que arroje nueva luz sobre los últimos conflictos de la Persia sasánida con el Bizancio Justinianeo y Heraclida y con los ejércitos árabes del primer Islam.

The question of the number of troops that existed in the Sassanids' armies during the 6th and 7th century has received various answers. Answers that, paradoxically, have not taken into account the specific and multiple information that provide the sources of this period. From our side in this paper, we address this question taking into account all the sources, whether these are Byzantine, Oriental, Persian or Perso-Islamic, and we try to show that the careful study of the data and the critical comparison permits us to evaluate with extreme precision the military power of the Sassanian Persia and to establish a comparative basis to shed new light on the late conflicts between Sassanid Persia and the Justinian's or Heraclius' Byzantium as well as those with the Arab armies of early Islam.

\section{Palabras Clave - Keywords}

Persia; Sasánidas; Bizancio; ejército; Próximo Oriente; expansión árabe.

Persia; Sassanian; Byzantine; Army; Middle East; Arab expansion.

¿Con cuántos soldados contaban los ejércitos de la Persia sasánida en los días de su máximo poder y en los que se vio obligada a combatir a los conquistadores árabes? Paradójicamente y pese a que, como mostraremos de inmediato, las fuentes proporcionan abundantes datos y cifras para realizar una evaluación del poderío militar sasánida a fines del siglo VI y la primera mitad del VII, las cifras dadas por los historiadores de este periodo se basan más en sus propias y personales apreciaciones que en las cifras e informaciones que nos han legado los contemporáneos de los hechos.

* José Soto Chica: Universidad de Granada - Centro de Estudios Bizantinos, Neogriegos y Chipriotas de Granada. josesotochica@gmail.com. 
Lo arriba expuesto puede explicarse porque la historia de la Persia sasánida se ha hecho con frecuencia desde departamentos estancos, abordándola desde las fuentes bizantinas y orientales — griegas, armenias, siriacas, etc. — o bien tomando como base a las fuentes iranias y perso-islámicas. De manera que los datos y conclusiones que se obtienen a partir de un grupo de fuentes y desde una disciplina, la bizantinística, no se relacionan ni contrastan con las resultantes del estudio del otro grupo de fuentes y especialidad, la iranología. A lo largo de varios trabajos sobre la época y los ejércitos bizantino y persa de este periodo entre fines del siglo VI y primera mitad del VII, hemos abordado los diferentes temas desde una perspectiva integradora en la que se tuvieran en cuenta a todas las fuentes y atendiendo también a la bibliografía contemporánea tanto de la bizantinística como de la iranología.

Será desde el método arriba referido desde el que abordaremos la cuestión. El resultado no sólo nos ofrecerá una mejor base para el estudio de las últimas guerras romano-sasánidas y de la conquista islámica de Irán, sino también y ante todo, una sólida base a partir de la cual poder comparar el poderío militar persa con el del Bizancio justinianeo y heraclida.

Las fuentes son pródigas a la hora de proporcionarnos información sobre los ejércitos sasánidas de este periodo, pero, pese a ello, los historiadores contemporáneos no terminan de solventar el problema del número real de fuerzas con las que Cosroes I y sus inmediatos sucesores contaban. Por citar un destacado ejemplo, K. Farrokh, acepta en una de sus obras - sin crítica alguna - la noticia de al-Tabarï de que Persia disponía de un total de 70.000 guerreros en su ejército a la par que también acepta los datos de la Crónica de 1234, que señala que en un solo frente y en 573, Cosroes dispuso de 63.000 soldados profesionales y 120.000 soldados de leva reclutados para tal fin entre el campesinado persa. No sólo eso, el afamado iranólogo completa sus contradicciones concluyendo en otra de sus obras que la cifra de 70.000 guerreros sólo se refiere a los savaran. Farrokh no entra a fondo en este problema, pues no establece la adecuada relación entre un dato y otro, sino que se limita a darlos sin confrontación o matización alguna, dejando así sin resolver el problema del número de hombres del que disponía Persia en sus ejércitos. Además, se equivoca cuando fecha el dato de al-Tabarï, pues dice que corresponde al del ejército sasánida en 578, pero realmente la fecha correcta sería 588, cuando Bahram Chobin marchó contra los turcos. Es ese episodio y no otro, el que narra al-Tabarï cuando proporciona su información sobre el número de guerreros inscritos en las listas de las oficinas del palacio imperial persa (Farrokh, 2005: 23 y 42 y Farrokh, 2007: 186). Por su parte, Howard-Jonhson, desde el campo de los estudios del ejército romano tardoantiguo y bizantino, evaluó el potencial del ejército sasánida de Cosroes I en unos 180.000 efectivos y lo hizo tomando como base un dato aislado y una suposición propia: los 60.000 hombres desplazados a Lázica, Caúcaso Suroccidental, por Cosroes I en 554-557 y su teoría de que las dos grandes potencias, Bizancio y Persia, sólo podían concentrar en un frente a un tercio de sus efectivos. (Howard-Jonhson 1995: 157-226).

En apariencia, la información que nos proporcionan las fuentes más fiables de la época se contradicen, aunque no es cierto, como veremos.

Dos noticias sobre los efectivos humanos con que contaba el ejército sasánida de este periodo han atraído especialmente la atención de los especialistas:

$1^{\circ}$ ) a proporcionada por la obra siríaca conocida como Chronicon Anonimum o Crónica del año 1234, que recoge noticias de crónicas sirias muy anteriores. Este texto nos informa, con una precisión pasmosa, sobre el ejército que Cosroes I llevó en 573 ante los muros de Dara para asediarla y tomarla. El anónimo cronista, que transcribía información de los siglos VI y VII, nos dice que el Rey de reyes persa contaba con un ejército de 23.000 jinetes, 40.000 infantes y 120.000 campesinos (Crónica de 1234: 66, 203.20-205.7). 
$2^{\circ}$ ) La reseñada en la obra del historiador perso-islámico al-Tabarï, que tuvo acceso a documentos persas del último periodo sasánida. Este historiador nos ofrece la noticia, a propósito de la expedición que Bahram Chobin estaba preparando en 588 contra los turcos occidentales, de que Bahram marchó al combate con 12.000 guerreros escogidos entre los 70.000 cuyos nombres figuraban en los rollos de las oficinas imperiales (al-Tabarï: V, 992, 302).

Aparentemente tenemos aquí dos noticias que se contradicen profundamente. ¿Cómo es posible que Cosroes I, en 573 y en un solo frente, fuese capaz de disponer de un total de 183.000 hombres, mientras que apenas unos años más tarde, en 588, y según la noticia de alTabarï, Persia sólo disponía de un total de 70.000 guerreros inscritos en las listas de las oficinas imperiales? ¿Contradicción? Sólo en apariencia, pues en realidad si se comparan adecuadamente y se tienen en cuenta las informaciones de las demás fuentes de la época, los datos de la Crónica de 1234 y de al-Tabarï se complementan perfectamente y nos proporcionan la base para establecer, por primera vez, una estimación fiable del número de hombres que integraban el ejército de Cosroes I Anusirwan y de sus inmediatos sucesores.

El primer paso será señalar que en el ejército sasánida de finales del siglo VI y del primer tercio del siglo VII, confluían una serie de peculiaridades que lo diferenciaban notablemente del ejército de la Romania y que hay que tener muy en cuenta para establecer cuál era el verdadero número de sus efectivos. Una de esas peculiaridades es la de que el ejército persa combinaba en su seno cuatro tipos de reclutamiento y, por lo tanto, de efectivos:

$\left.1^{\circ}\right)$ contingentes que militaban en lo que hoy llamaríamos «ejército profesional» que formaban la caballería pesada persa - los savaran - reclutados entre las distintas clases que componían la nobleza irania, fundamentalmente entre los dehqans y los azadan. Los savaran eran guerreros altamente entrenados, armados y montados a costa del erario público, del cual recibían también una soldada permanente y regular.

$2^{\circ}$ ) soldados también pertenecientes a ese «ejército profesional» que militaban en los cuerpos de infantería regular, ya pertenecieran éstos a los contingentes de infantería pesada - como los famosos infantes daylamitas - ya formasen parte de las compañías de arqueros de línea. Estos soldados de a pie iranios eran proporcionados por los príncipes y jefes de los pueblos montañeses, y por los guerreros del norte y del sureste de Persia, y recibían a cambio de sus servicios, bien una soldada, o bien tierras u otros beneficios. Además, estos infantes persas estaban excelentemente equipados y entrenados.

$3^{\circ}$ ) los contingentes de hombres que se alistaban en las compañías mercenarias y_extranjeras de caballería pesada y ligera, que con frecuencia militaban en el ejército persa y que procedían o bien de los pueblos vasallos del imperio (armenios, iberos y albaneses caucásicos o árabes lahmíes), o bien de compañías mercenarias reclutadas entre pueblos situados fuera de las fronteras del Eranshar. Todos estos hombres recibían una soldada por sus servicios, como en el caso de las compañías mercenarias, o bien eran aportados al ejército persa por los príncipes feudatarios del imperio en virtud de sus obligaciones militares hacia el Rey de Reyes de Persia. Estas tropas mercenarias o feudatarias no constituían, por lo general, una parte permanente del ejército, sino que solían ser reclutadas para un tiempo limitado, como la duración de una campaña o de una guerra.

$4^{\circ}$ ) la gran masa de infantes ligeros, reclutados a partir de levas forzosas de campesinos, quienes no recibían sueldo alguno por su servicio militar y eran alistados sólo en caso de guerra y licenciados no bien ésta terminara. Estos hombres, estaban tan deficiente- 
mente armados y entrenados que los autores romanos, griegos, sirios y armenios los denominan con los despectivos epítetos de «campesinos» $\mathrm{y}$ «sirvientes».

El anónimo autor sirio de la Crónica de 1234 separaba a la infantería de Cosroes plantada ante los muros de Dara en dos grupos bien definidos: los verdaderos infantes, posiblemente compañías de arqueros y de infantería pesada, que según el cronista sumaban 40.000 hombres, y los «campesinos» que, en número de 120.000 , se dedicaron durante el asedio a cavar trincheras, fortificar el campamento persa, construir terraplenes y máquinas de asedio, cavar minas y en lanzarse, en sangrientas oleadas, contra los muros de la gran ciudad-fortaleza; auténtica carne de cañón destinada a agotar las fuerzas de los defensores y a preparar así los verdaderos ataques que la infantería de línea lanzaba tras ellos (Crónica de 1234: 66, 203.20-205.7). Procopio de Cesarea tenía la misma opinión que el cronista que acabamos de citar, ya que, para él, los infantes persas proporcionados por la leva forzosa no eran sino «campesinos», hombres sin valor militar alguno, pobremente equipados y sólo aptos como trabajadores y como criados de los verdaderos soldados persas, los jinetes, esto es: los savaran (Procopio, Guerra persa: 93). Pueden hallarse otras descripciones desfavorables de la infantería ligera persa en las que se incide en su condición de reclutas procedentes de levas forzosas y sin sueldo, en su deficiente armamento y entrenamiento, y en su falta de valor (Amiano Marcelino: 23.6.83).

Así, el ejército persa se componía de fuerzas permanentes y no permanentes, de fuerzas profesionales y no profesionales, alistadas mediante diversos procedimientos: contingentes de guerreros nobles cuyos sueldos y equipo eran sufragados por el imperio, mercenarios, contingentes de auxiliares aportados por príncipes vasallos, y levas forzosas de campesinos sin entrenamiento ni armamento regular.

Habrá pues que distinguir, desde un principio, entre la fuerza que los persas podían alinear en una determinada guerra o campaña, y la fuerza real, permanente y disponible en todo momento; también entre los distintos grupos de guerreros y soldados que militaban o podían llegar a militar en el ejército persa. Si se realiza esto, desaparece la aparente contradicción que mantenían la Crónica de 1234 y al-Tabarï, y la que éste parecía sustentar frente al resto de las fuentes que ofrecían datos sobre el número de efectivos de los ejércitos sasánidas que combatieron contra romanos, turcos y árabes.

La información de al-Tabarï referente al hecho de que en las listas del ejército figuraban un total de 70.000 guerreros, no se refiere al total de hombres que componían los ejércitos del Rey de Reyes de Persia, sino al número de savaran pertrechados y pagados por el erario imperial (Farrokh 2007: 186.). Esto es evidente si se realiza una lectura detenida de al-Tabarï y se contrasta con la información de otras fuentes, sobre todo con las noticias que Firdusi nos ofrece para el mismo episodio. Recuérdese que Al-Tabarï colocaba el dato dentro del relato sobre la expedición de Bahram Chobin contra los turcos occidentales. Este relato, confirmado por las demás fuentes persas, nos dice que el Shahansha Ormuz IV fue atacado por los turcos occidentales en 588. Sabedor del peligro que entrañaba el ataque de los turcos kok en un momento en el que las victorias militares del emperador Mauricio estaban llevando a Persia a la derrota, Ormuz encarga a su mejor general, Bahram Chobin que preparara la defensa del Eranshar contra los turcos. Bahram Chobin, decidido a lanzar un devastador contraataque contra los turcos, marchó contra ellos a la cabeza de un ejército de guerreros escogidos. Selecciona pues, a 12.000 guerreros — 9.000 según Firdusi - de entre el total de 70.000 cuyos nombres aparecían en las listas de las oficinas persas y parte contra el enemigo. Los turcos, que poco antes habían movilizado contra Persia a un ejército de 110.000 jinetes (al-Tabarï: vol. V, 153) y que, al decir de Mas'udi, habían reunido en 588 a 400.000 guerreros para atacar al Eranshar (Mas'udi: I, §237), son completamente derrotados y su rey es muerto en batalla por mano del 
propio Bahram Chobin, quien vuelve a extender el dominio persa hasta Balj y a fijar la frontera oriental de Persia en la orilla meridional del río Oxus (al-Tabarï: V, 301-303; Firdusi: VI, 491502; Mas'udi: I, §237; Teofilacto Simocata: 3, 18,13; Sebeos: 11-12; Farrokh, 2005: 53-54; Christensen, 1944: 443-444).

Hasta aquí el relato de la expedición de Bahram Chobin contra los turcos en 588-589. Se habrá observado que el ejército que comandaba el general Bahram Chobin es muy exiguo: 12.000 guerreros (9.000 según Firdusi); lo es más aún si se compara con los 110.000 hombres - al menos - que podía llegar a movilizar el soberano turco a quien se iba a combatir, o con las cifras que sobre el número de hombres que militaban en otros ejércitos persas de la época nos ofrecen el resto de las fuentes. Así, se dice que los persas alinearon en Dara contra Belisario a 50.000 hombres. Procopio dice que los persas alinearon en un principio a 40.000 hombres contra los 25.000 que les oponía Belisario, pero que tras una jornada dedicada a escaramuzas y desafíos personales, otros 10.000 persas se sumaron a los que ya se hallaban frente a los romanos, por lo que al cabo fueron 50.000 los que militaban en el ejército que luchó en Dara (Procopio, Guerra Persa: I, 13-14, 86-88). Por otra parte, se dice que Cosroes disponía en 554, en Lázica, de un ejército integrado por 60.000 guerreros (Agatías: 3,17, 3-6); que en agosto de 573, Persia envió un ejército de 20.000 hombres a luchar contra los rebeldes armenios (Sebeos: 9) y que a fines de ese mismo año, cuando aún permanecían en Armenia los 20.000 antes citados, Cosroes llevó a un total de 183.000 soldados ante los muros de Dara (Crónica de 1234: 66, 203.20 - 205.7). También se nos informa de que unos meses más tarde, tras la toma de Dara, Cosroes marchó al frente de 140.000 hombres contra el ejército romano que asediaba Nísibe (Greatrex et alii, 2002: 150); que en 591, en la gran batalla que puso final a la guerra civil persa de 589-591, Cosroes pudo alinear a 20.000 persas junto a los 40.000 romanos que le envió Mauricio en su ayuda y enfrentarse así, con superioridad numérica, a los 40.000 guerreros persas que formaban el ejército del usurpador Bahram Chobin. Teofilacto Simocata ( Teofilacto 5.9.4, p. 144) dice que Cosroes II logró reunir contra Bahram Chobin a un total de 60.000 hombres, incluyendo entre ellos a los aliados romanos, cuyo número sabemos por Agapios (Agapios 185, 445) y por la Historia Nestoriana (Historia Nestoriana, 146, LVIII, p. 466) que era de 40.000. Esto quiere decir que Cosroes, destronado y recién regresado a Persia, fue capaz de convocar a 20.000 guerreros persas a su campo. Bahram Chobin, por su parte y según la misma noticia ofrecida por Teofilacto, logró alinear frente a Cosroes y sus aliados romanos, a 40.000 hombres.

Tampoco fueron menores los efectivos persas durante la gran guerra romano-persa de 603-628. Así, en 623, Cosroes II esperaba en Ganzak a Heraclio al frente de 40.000 guerreros (Teófanes: 6114, 307.), mientras que en 624, el spahbad Sain marchó contra Heraclio al frente de 30.000 hombres (Sebeos: p. 82.); dos años más tarde, en 626, el mismo general persa avanzó contra el hermano de Heraclio, Teodoro, a la cabeza de más de 50.000 guerreros Teófanes (Teófanes, 6117, 315) relata que Cosroes II le envió a Sain 50.000 hombres que hasta entonces habían militado en los ejércitos de Sharbaraz; se suponía que esos hombres iban a reforzar el ejército de Sain y que, por lo tanto, este sería mucho mayor. Dado que se nos dice también que Sharbaraz seguía al frente de otro ejército persa que ese mismo año se plantó ante Constantinopla, es fácil inferir que, tanto Sharbaraz como Sain, estaban al mando de ejércitos muy superiores a 50.000 hombres.

Todavía a finales de 627, cuando ya la guerra se mostraba contraria a Cosroes II y los ejércitos comandados por Sharbaraz desertaban de su campo, el Rey de Reyes aún pudo reunir un ejército tan numeroso como para que, en la batalla de Nínive, Heraclio le inflingiera 50.000 bajas (Agapios: 204, 464). Incluso cuando los ejércitos árabes asediaban al imperio, y las guerras civiles y las conjuras palaciegas minaban su capacidad de resistencia ante los invasores, Persia 
era capaz de convocar grandes ejércitos en su defensa. Así, en 636, 80.000 guerreros fueron reunidos en Qadesiya para luchar contra los ejércitos del califa 'Umar (Sebeos: 98.) y en 642, otros 60.000 fueron alineados en las filas del último ejército real sasánida, para oponerse en Nehavend a los invasores árabes que trataban de pasar a la meseta irania (Sebeos: 104).

Acabamos de mostrar unos pocos ejemplos sobre el tamaño habitual de los ejércitos sasánidas. Nuestro propósito es ofrecer una base comparativa con la que contrastar los datos ofrecidos por al-Tabarï sobre el ejército seleccionado por Bahram Chobin para luchar contra los turcos. Como ha podido comprobarse, es bastante chocante - si creemos a pie juntillas la información de Tabarï, Firdusi y otras fuentes perso-islámicas - que Bahram Chobin contara para salvar al Eranshar de una invasión en toda regla, con el ejército más pequeño de todo el periodo. Al comparar los 12.000 guerreros que al-Tabarï le atribuye, con los 60.000 movilizados en Lázica, los 183.000 puestos en combate contra Dara, los 40.000 comandados por Cosroes II en 623 o los 60.000 reunidos en 642, resulta evidente que la cifra dada por al-Tabarï es muy baja. Esta cifra es poco verosímil, pues no es lógico pensar que ante la amenaza que significaban los turcos (a la sazón la mayor potencia de Asia central y uno de los cuatro grandes imperios que dominaban Eurasia) Persia enviara contra ellos a sólo 12.000 hombres, por muy escogidos y valientes que estos fuesen. Persia, a lo largo de más de un siglo, fue siempre capaz de oponer grandes ejércitos a sus enemigos, ejércitos que superaban a menudo la cifra de 40.000 hombres. ¿Por qué razón iba a ser diferente en el caso de Bahram y los turcos? ¿Por qué Persia, ante el ataque de un enemigo tan peligroso iba a responder enviando contra ellos a un ejército tan excepcionalmente pequeño?

En definitiva: el número de hombres que según al-Tabarï formaban el ejército que Barahm Chobin tenía que llevar contra los persas es demasiado bajo y no se corresponde con las cifras que las fuentes más cercanas a la época sasánida suelen dar para sus ejércitos. Tendremos pues que concluir que los 12.000 guerreros escogidos por Barahm Chobin sólo constituían una parte de su ejército, los savaran, auténtica punta de lanza y base de cualquier ejército persa. Y es que es muy frecuente que tanto al-Tabarï, como Firdusi, Mas'udi, Tahalibi y el resto de las fuentes árabes y perso-islámicas, al referirse a los ejércitos del Eranshar mencionen sólo a la caballería. No es de extrañar que así sea pues, al fin y al cabo, era la pieza esencial del ejército persa.

Los savaran eran los auténticos guerreros, los únicos que figuraban como tales en las listas del censo persa que agrupaba a la población según la casta a la que pertenecieran (Firdusi: VI, 512 y Mas’udi: I, §154; Christensen, 1944: 319-320; Farrokh, 2005: 1-8). Sólo ellos eran nobles y, con mucha frecuencia, sólo ellos atrajeron la atención de cronistas, historiadores y poetas. De hecho, fueron los descendientes de los savaran - principalmente los de los dehqans, la nobleza local aupada por las reformas militares de Cosroes I, los que transmitieron las viejas historias y noticias de los tiempos sasánidas a los escritores islámicos de los siglos IX, X y XI, quienes, con mucha frecuencia, eran a su vez también dehqans y, por lo tanto, descendientes de los savaran. Así que no es de extrañar que sean los savaran, y no otros, los que centren la atención de los eruditos perso-islámicos que nos transmitieron la mayor parte de la historia sasánida.

Además, Firdusi nos confirma lo que acabamos de afirmar: que el relato de al-Tabarï se refiere sólo y exclusivamente al número de savaran, es decir de jinetes de la nobleza guerrera de Persia, escogidos por el general Bahram Chobin entre el total de 70.000 que figuraba en las listas, y no al conjunto de soldados de diversas clases que componían el ejército del Eranshar. En efecto, Firdusi, al ofrecernos su relato del episodio de al-Tabari que estamos analizando, es decir, el que nos describe al ejército de Bahram Chobin y su posterior campaña contra los turcos occidentales en 588-589, relata cómo Bahram Chobin, una vez realizada la selección de su ejército, le pasa revista. En ella sólo figuran jinetes (savaran) pesadamente armados que Firdusi, con el regocijo propio del descendiente de una antigua familia de savaran, describe 
con pormenorizado detalle, ala tras ala, deteniéndose en el nombre de sus oficiales, en la descripción de su armamento, en la alabanza del vigor y prestancia de sus caballos, etc. Sólo jinetes, repitámoslo. Eso es lo único que aparece en la revista de tropas que nos relata con tanto detalle Firdusi (Firdusi: VI, 492-493), un acomodado dehqan persa del Jorasán que —como al-Tabari- recurría a menudo a las crónicas familiares, a los recuerdos y tradiciones de las familias de sus compañeros de casta para reconstruir el esplendoroso y añorado pasado del Eranshar.

Firdusi no es el único autor perso-islámico que se comporta de esta manera, ya que también al-Tabarï suele reservar su atención para los savaran. Un ejemplo claro lo tenemos en la narración que nos ofrece sobre la batalla de Nínive en la que, en diciembre de 627, Heraclio quebró la resistencia persa. Pues bien, al-Tabarï, al narrarnos este decisivo encuentro, dice que Cosroes II sólo envió contra Heraclio a 12.000 guerreros, de nuevo se repite la cifra y eso que Heraclio avanzaba contra él a la cabeza de un ejército que contaba entre sus filas con un mínimo de 40.000 soldados. ¿No es un poco extraño que Cosroes II enviara tan pocos hombres a contener a Heraclio? Y sobre todo ¿cómo es posible que el ejército persa, tras ser derrotado por Heraclio, dejara sobre el campo a 50.000 de sus hombres cuando al-Tabarï afirmaba que sólo reunía a un total de 12.000? El dato que acabamos de facilitar sobre el número de bajas que sufrió en la batalla el ejército persa nos lo proporciona Agapios, una de las fuentes más ricas y precisas con las que contamos para el estudio de los dos últimos años de la guerra de Heraclio contra Cosroes II. Agapios deja en evidencia, una vez más, a al-Tabarï. Y es que alTabarï, como ya había hecho en su anterior relato sobre Bahram Chobin y su campaña contra los turcos, y al igual que hace Firdusi, sólo está mencionando a los savaran. Por eso sólo cuenta a 12.000 guerreros en las filas del ejército persa que peleó en Nínive en 627, porque esa cifra sólo representaba el número de jinetes, de savaran, que militaba en dicho ejército. Naturalmente, el ejército debió de contar también con contingentes de infantería de diversa clase, máxime cuando la totalidad de nuestras fuentes está de acuerdo en que la batalla de Nínive fue extraordinariamente reñida y dura, lo que no hubiera sido posible si Heraclio y sus al menos 40.000 soldados, sólo hubiesen tenido frente a ellos a 12.000 hombres. No fue así, sino que tuvo que ser un ejército persa tan numeroso como para dejar sobre el campo de batalla a 50.000 de sus hombres. Esto último es una prueba más que evidente, de que superaba esta última cifra y de que el dato de al-Tabarï sólo puede referirse, también en este caso, al número de savaran y no a la totalidad del ejército persa. La batalla de Nínive fue extraordinariamente dura y reñida, tanto que, para quebrar el frente persa, el emperador Heraclio tuvo que combatir en primera línea y de forma arriesgada, recibiendo heridas él y su caballo (Teófanes: 6118, 318-320; Patriarca Nicéforo: cap. 14; Historia Nestoriana: 221-222, LXXXVII, pp. 541-542; Sebeos: pp. 84-85; Miguel el Sirio: II, lib. XI, III p. 409; al-Tabarï: V, 1004, pp. 322-323. En cuanto a las más de 50.000 bajas sufridas por los persas en esta batalla ver Agapios: 204, p. 464; Teófanes: 6118,318 ).

Además, vamos a ofrecer, a continuación, una prueba concluyente e inequívoca que muestra que efectivamente, tal y como se podía colegir del relato que Agapios daba sobre el número de bajas sufridas por el ejército persa en Nínive, el ejército persa que allí luchó era mucho mayor que el que aparentemente señalaba al-Tabarï. Esa prueba nos la proporciona Teófanes, quien escribió unos cien años antes que al-Tabari y que tomó de Jorge de Pisidia - contemporáneo de los hechos - su información sobre Heraclio y sus campañas persas. Pues bien, Teófanes, en su extenso y preciso relato de la batalla de Nínive, nos dice que Heraclio capturó en ella 28 estandartes persas y que en este número no se contaba el de los estandartes dañados y rotos que los persas habían dejado en tierra. Ahora bien, sabemos que los estandartes persas eran ostentados por los drafsh, los regimientos persas de mil hombres; de hecho drafsh significaba originalmente «estandarte» y sólo pasó a designar a una unidad persa de mil hombres cuando 
éstas recibieron el privilegio de ser identificadas por llevar su propio drafsh. Por lo tanto, si Heraclio tomó a los persas 28 drafsh, quiere decir que había más de 28.000 hombres frente a él, pues Heraclio no contó los estandartes persas que resultaron dañados durante el combate, ni pudo tomar todos los drafsh del ejército persa ya que éste siguió, tras once horas de batalla y pese a ser derrotado, sobre el campo de combate y en buen orden. De hecho los persas sólo se marcharon al anochecer, y continuaron siendo tan numerosos y disciplinados como para seguir intentando oponerse al avance romano durante las siguientes semanas. Habrá pues que concluir que el número total de persas contra los que se enfrentó Heraclio en Nínive tuvo que ser mucho mayor que los 12.000 guerreros mencionados por al-Tabari y que el de los 28.000 hombres representados por los 28 estandartes capturados por Heraclio. Su número debió de ser mucho mayor, tanto como para dejar sobre el campo de batalla las más de 50.000 bajas señaladas por Agapios y como para que, tras sufrir semejante debacle, ser capaz de seguir cohesionado y combatiendo.

Por si todo lo anterior fuera poco y para demostrar que en Nínive no sólo pelearon unidades persas de caballería sino también de infantería, señalaremos ahora que Teófanes también nos informa de que entre los persas había numerosa infantería. De hecho, tuvo que haber una infantería pesada persa de tan buena calidad como para ser capaz de mantenerse en buen orden sobre el campo de lucha, cuando ya las demás unidades persas flaqueaban, y tan aguerrida como para herir durante la misma al emperador Heraclio y a su caballo.

No hay pues duda, tal y como acabamos de mostrar, al-Tabarï, en la inmensa mayoría de las citas que hace sobre los ejércitos persas, menciona sólo el número de los contingentes de savaran, tal y como también hacía Firdusi y el resto de los autores perso-islámicos. Por lo mismo, la selección de 12.000 hombres realizada por Bahram Chobin en 588 que nos narra alTabarï, y que nos confirma y matiza Firdusi, sólo puede referirse a la selección de la caballería del ejército, de los savaran que iban a formar parte de él. Por tanto, la cifra de 70.000 guerreros de entre cuyas filas Bahram llevó a cabo la selección de sus 12.000 valientes, sólo indica el número de hombres válidos para el combate que aparecían registrados en las listas de la casta de los guerreros en aquel año de 588 .

En definitiva: Bahram Chobin marchó contra los turcos con un ejército cuyo eje principal - como siempre en un ejército persa - lo constituía la caballería formada por los savaran, pero que incluía también a contingentes de infantería y de otros cuerpos con toda seguridad. De hecho, los manuales de estrategia y táctica persas de la época, indicaban con claridad que los ejércitos sasánidas que marcharan a combatir a los turcos y a otros pueblos de la estepa, se hallasen siempre formados tanto por tropas de infantería como de caballería. De esta forma, las tácticas esgrimidas por los generales persas contra los turcos, se basaban en una acertada combinación de los recursos y habilidades de los contingentes de infantería y de caballería que debían de actuar de forma sincrónica y coordinada para obtener la victoria. Sabemos que tanto Bahram Chobin (en las campañas de 588-589) como Smbat Bagratuni (en la de 618-619) recurrieron a las tácticas establecidas por los manuales tácticos persas para enfrentar formaciones nómadas. Por lo tanto, debían de disponer en sus ejércitos obligatoriamente de contingentes de caballería y de infantería. Esta realidad se hace aún más evidente y clara cuando se sopesa que las operaciones bélicas desarrolladas por ambos generales contra los turcos y sus aliados conllevaron el asedio y la toma de fortalezas y ciudades tan fuertes como Balj, lo que hubiese sido de todo punto imposible sin la participación en dichas operaciones de fuertes contingentes de infantería. Tanto la estrategia de defensa de la frontera turania de Persia, como la táctica recomendada para las batallas contra los turcos y eftalitas, implicaban el uso de infantería pesada y ligera, así como de tropas auxiliares. De hecho, la estrategia sasánida de defensa de su frontera oriental contra eftalitas y turcos se basaba en la construcción y uso de un limes en profundidad, cuyas escalonadas defensas servían como bases logísticas del ejército persa y puntos de partida 
para su contraataque; a la par que, taponando determinados pasos de río y montaña y dejando otros abiertos, encauzaba las invasiones y algaradas nómadas hacia unos puntos concretos del territorio en los que el ejército sasánida se reunía y en los que le era favorable el terreno, en caso de librar batalla. El uso de esta estrategia táctica que hemos descrito en el texto, implicaba el uso de infantería en combinación con caballería. Si se lee atentamente la descripción de la gran batalla librada por Barahm Chobin contra los turcos, se advertirá que la infantería tuvo que estar presente, aunque no se la mencione explícitamente, pues de otro modo no se explican ni la táctica del general persa, ni el desarrollo del combate, ni la posterior conquista de fortalezas tan señaladas como Balj. (Firdusi: VI, 493-502; Farrokh, 2005: 41-42)

Sin embargo, pese a que es indudable que la táctica sasánida empleada por Bahram Chobin para combatir a los turcos implicaba el uso combinado de contingentes de infantería y de caballería, en la citada revista de tropas narrada por Firdusi sólo se menciona a los savaran. Y es lógico que así sea, pues — como hemos visto- sólo estos importaban a los descendientes de los antiguos nobles persas que convertidos al Islam y transmutados en historiadores, poetas y geógrafos, nos transmitieron la mayor parte de la historia sasánida que conservamos. Al fin y al cabo, sólo los savaran eran verdaderamente «guerreros» en el sentido mazdeísta y sasánida del término, y por lo tanto, sólo ellos figuraban en las listas de la casta de los guerreros. Por lo mismo, en la Persia post-sasánida de los días de al-Tabarï, Firdusi, Daqiqi, Al-Balamï, Mas'udi o Tha'labi, sólo de ellos se podían haber salvaguardado datos certeros y precisos.

¿Qué tenemos entonces aquí? Un dato precioso que aflora ante nosotros y nos proporciona el punto de partida para comenzar a establecer el verdadero potencial militar con el que contaba la Persia sasánida de fines del siglo VI y de la primera mitad del VII. Un dato que, una vez sometido a la necesaria crítica, nos informa sobre el número exacto de hombres que militaban en la caballería pesada persa, el verdadero espinazo de sus ejércitos y de su sociedad. Ese dato no es otro sino que en 588, Persia disponía de 70.000 savaran inscritos en las listas de la casta de los guerreros.

Setenta mil savaran pesadamente armados, es una cifra que cuadra muy bien con los datos que nos proporcionan las fuentes. Firdusi, por ejemplo, nos informa de que Cosroes I envió contra Justiniano un ejército formado por 30.000 jinetes (Firdusi: VI, 153). Y 15.000 savaran tomaron parte en la algarada que Persia lanzó contra Siria en la primavera de 531 (Procopio: Guerra persa: I, 16, 6-10). Más tarde, en 573, Cosroes llevó consigo a 23.000 jinetes en su expedición contra Dara y, a fines de ese mismo año, llegó a reunir 40.000 (Crónica de 1234: 66, 203.20 - 205.7; Greatrex el alii, 2002: 150). Mientras que en uno sólo de sus cuerpos de élite, el de los zhayedan o inmortales, se podían contar 10.000 jinetes extraídos de entre las filas de los savaran (Farrokh, 2005: 6 y 29). ¿30.000, 15.000, 23.000, 40.000, 10.000? Son contingentes de caballería muy numerosos y que se reúnen en un único punto, una única campaña, un único frente o en un único cuerpo. Esto lleva a pensar inevitablemente que el total debía de ser mucho más numeroso, pues Persia tenía que guarnecer cuatro fronteras y a menudo, como en 573, hacer frente a varios peligros a la vez. O dicho de otro modo: si Cosroes I podía llegar a reunir 40.000 jinetes persas en un sólo punto, eso quiere decir que la cifra total de jinetes (savaran) que militaban en su ejército era muy superior a ese número y por lo tanto, es muy probable que la cifra total de 70.000 jinetes sea muy posible.

Otras evidencias de lo acertado de nuestra conclusión las encontramos en un dato proporcionado por Mas'udi. Cosroes II llevó a cabo en los días iniciales de su reinado, posiblemente hacia 603, una revista general de sus tropas. Estas revistas eran relativamente frecuentes, estaban rigurosamente reglamentadas y a ellas acudían los guerreros con sus caballos, armas, arneses y equipos en perfecto estado de revista. Estas revistas generales podían llegar a durar hasta 40 días (Farrokh, 2005: 230-231) y por lo tanto, y en aras de la seguridad del imperio, no acudían siempre a ellas todos los guerreros, sino sólo los que no estuviesen de servicio en las 
distintas guarniciones fronterizas o de cuantos se pudiera prescindir sin riesgo de desguarnecer por completo las fronteras. En cualquier caso, en estas revistas se concentraba al grueso de los efectivos del ejército permanente con el que contaba Persia. Pues bien, Mas'udi nos informa de que en un día de fiesta, Cosroes II pasó revista a su ejército y a su flota, y que reunió junto a él a 50.000 jinetes, una cifra de guerreros en la que no se incluía a los infantes (Mas'udi: II.231, II 232, 652, p. 244; al-Tabarï: V, 964-965, pp. 262-263).

El dato, unido a los anteriores, es bastante significativo. Si Persia, tras asegurar sus fronteras, podía aún convocar a una revista general a 50.000 guerreros de caballería, eso quiere decir que debía de contar con un total superior a esa cifra, un número que al-Tabarï nos transmitió y que hasta ahora, por falta de crítica adecuada, permanecía ignorado: esa cifra total de savaran en las filas de su ejército no es otra que la de los 70.000 soldados que al-Tabarï señala como inscritos en las listas de los guerreros en el año 588.

Ahora bien, si Persia disponía a fines del siglo VI de un total de 70.000 savaran en las filas de su caballería noble ¿cuál era el total de soldados de todo tipo que militaban en el conjunto de su ejército? Aquí es donde resulta útil traer a colación los datos de al-Tabarï que acabamos de cribar, para confrontarlos con los de la Crónica de 1234 y, a partir de ese primer paso, compararlos con los que nos proporcionan otros historiadores como Teófanes de Bizancio, Sebeos, Agatías, etc.

Bien, recuérdese que la Crónica de 1234 nos informaba de que Cosroes I puso ante los muros de Dara a un total de 183.000 hombres: 23.000 jinetes, 40.000 infantes y 120.000 "campesinos". Ya vimos a qué tipo de fuerzas del ejército persa se referían cada una de estas cifras y acabamos de mostrar que los 23.000 jinetes sólo representaban un tercio del total de la caballería irania de fines del siglo VI. De hecho, pocos meses después de su ataque a Dara, Cosroes I juntaría un total de 40.000 jinetes en una sola fuerza; esto es, más de la mitad del total de sus efectivos disponibles de esta clase de tropas.

Establecido lo anterior, nos centraremos ahora en el segundo grupo de fuerzas que señala la Crónica de 1234: los 40.000 infantes. Sabemos que Persia nunca fue rica en infantería pesada, ni en contingentes de arqueros regulares. La cifra de 40.000 infantes que nos ofrece la Crónica de 1234 debía de constituir el grueso de este tipo de fuerzas, pues es a ellos, sin duda, a la infantería pesada reclutada entre los daylamitas, los tchole, los bariz, los gelani, tabaristaníes, curdos y demás pueblos montañeses del norte y del sureste del Irán, y a los eficaces contingentes de arqueros profesionales dirigidos por los oficiales llamados tirbad, a quienes se refiere el anónimo autor de la Crónica de 1234. Como ya mostramos, los autores griegos, sirios y armenios sentían un hondo desprecio hacia la infantería persa de leva forzosa, de ahí que a sus miembros les asignasen epítetos como «campesinos» y «servidores». Muy diferente era la actitud que los historiadores y cronistas del ámbito de la antigua Romania mantenían hacia los daylamitas o hacia otros pueblos que militaban en la infantería regular persa. Éstos, pensaban, sí que eran verdaderos soldados y por lo tanto se les distinguía muy bien de la masa formada por las deficientes levas de campesinos persas que inflaban la cifra total de los ejércitos que Persia enviaba a luchar contra sus enemigos.

No tiene pues nada de extraño que la Crónica de 1234 distinga puntillosamente entre los verdaderos infantes persas y la masa amorfa e indisciplinada de las levas campesinas. Pero esos 40.000 infantes que menciona la citada crónica debían de constituir el grueso de su infantería regular. Lo creemos así porque cuando las fuentes ofrecen cifras precisas sobre contingentes persas de infantería pesada o de compañías de arqueros de línea, esas cifras son siempre relativamente pequeñas. Así, por ejemplo, Cosroes I envió en 570 a la conquista del Yemen a un contingente de infantería pesada formado por 800 soldados, 1.000, según otras fuentes. Al-Tabarï (al-Tabarï, V, 889, 160) dice que la expedición a Yemen estaba a las órdenes del comandante de un regimiento de daylamitas, pero más adelante (al-Tabarï: V, 948, 239), 
en otra versión con algún tinte fantasioso, afirma que fueron 800 los hombres enviados a Yemen. No se debe meditar mucho sobre lo inverosímil de la segunda versión de al-Tabarï que transforma a los daylamitas en presidiarios. Pocos años más tarde, en 573, Cosroes enviaría a Yemen un segundo contingente de infantería de línea, formado esta vez por 4.000 soldados (al-Tabari: V, 957, 251). Veinte años atrás, en Lázica, en 554, Agatías nos señala un contingente de infantería pesada persa formado por 3.000 daylamitas (Agatías: III, 17, 6-7); unos años antes, en 542, en la batalla de Anglón, Procopio nos relata cómo 4.000 arqueros de línea persas fueron capaces de derrotar, mediante una eficaz emboscada, a un ejército romano de 30.000 hombres (Procopio, Guerra Persa: II 25, pp. 273-274; Farrokh, 2005: 26). Por último, para no extendernos, recordaremos aquí que en los días de la conquista árabe del Eranshar, un contingente de infantería pesada persa formado por 4.000 dailamitas se pasó a los árabes facilitando enormemente su victoria sobre el ejército sasánida (Al-BalädurÏ: I, 440-441; Farrokh, 2005: 24-25; Kennedy, 2007: 151).

Se trata pues de cifras muy modestas y seguramente expresan lo que también podemos constatar a través del estudio de las batallas de este periodo: que la infantería regular persa (es decir, su infantería pesada y sus arqueros de línea) era poco numerosa e importante en comparación con su magnífica caballería pesada y con sus numerosos contingentes de infantería de leva. De ahí que la cifra de 40.000 hombres dada por la Crónica de 1234 sea posiblemente la del grueso de los efectivos de este tipo de fuerzas en el ejército persa de este periodo. El grueso pero no el total, pues recordemos que desde 570 había contingentes de infantería pesada destacados en el Yemen y que la adecuada defensa de las fortificaciones del Cáucaso, de Gurgan y de la frontera del Oxus, exigían el establecimiento permanente de contingentes de infantería pesada y de compañías de arqueros.

Teniendo en cuenta todo lo anterior es muy probable que el total de infantería regular y permanente del que dispusiera Persia en este periodo estuviese en torno a los 50.000 hombres, no bajando en cualquier caso de esta cifra ni superando la de 60.000.

Por lo tanto, el ejército permanente y, por así decir, profesional de Persia a fines del siglo VI sumaba un total aproximado de 120.000 hombres: 70.000 jinetes pesados excelentemente armados, montados, entrenados y pagados, y 50.000 rudos infantes extraídos de los pueblos montañeses del norte y del sureste de Persia y de lo mejor del campesinado iranio. Ciento veinte mil hombres es una fuerza considerablemente menor que aquella con la que contaba la Romania por esos mismos años y que establecimos en un trabajo anterior en 150.000 hombres para sus ejércitos de campaña y 100.000 para sus tropas de frontera.(Soto, 2010: 89) Ahora bien, se recordará que Persia, llegado el caso, podía disponer de otras fuentes de recursos militares: los proporcionados por los príncipes vasallos y por la contratación de mercenarios, y los que aportaban las levas forzosas de campesinos.

Comenzaremos pues por las tropas que los príncipes vasallos del Shahansha tenían que sumar a los ejércitos del Rey de Reyes de Persia cuando éste lo estimaba oportuno. Eran muchos los príncipes y jefes locales en lugares extremos y fronterizos del imperio que contribuían con sus contingentes de guerreros al esfuerzo bélico del Eranshar. Entre ellos destacaban los soberanos de los árabes lahmíes, los nobles de la Perso-Armenia, el rey de los íberos del Cáucaso, los jefes de algunos grupos de heftalitas y de turcos asentados en el Eranshar, el Zunbíl del valle del río Helmans y del Zabulistán, el Sul de Gurgan, los príncipes de los albaneses caucásicos y el Kabulsha del valle de Kabul. ¿Cómo se estructuraba el apoyo militar de estos príncipes feudatarios al Eranshar? Un ejemplo: Gurgan, tierra de frontera por antonomasia, estaba gobernada por príncipes locales hereditarios vasallos del rey persa. Cuando los musulmanes llegaron a esta remota región, firmaron con el Sul de Gurgan un tratado que era un simple calco de la situación anteriormente reinante en el país: sencillamente el Sul de Gurgan trasladó sus obligaciones desde el rey persa hasta el representante del Califa en el Irán. Por el 
tratado firmado con los árabes, el Sul de Gurgan seguía ejerciendo su autoridad sobre todo el país y gobernándolo a su antojo, mientras que a los habitantes se les permitía conservar su religión mazdeísta, sus bienes y armas. Sus únicas obligaciones hacia los árabes serían las de no atacarles y ayudarles militarmente proporcionándoles contingentes de guerreros. Se estipuló también que si en algún momento los árabes no necesitaban ayuda militar, ésta se sustituiría por un impuesto pagado por la totalidad de la región. Gurgan permaneció siendo un país prácticamente independiente hasta fines del siglo VIII. Acerca del tratado de los árabes con el Sul de Gurgan (al-Balädurï: II, 9-43; Kennedy, 2007: 208-209). En cuanto al Zunbíl del valle del Helmans y del Zabulistán, y al Kabulsha del valle de Kabul, que se resistieron ferozmente a la conquista islámica hasta el siglo XI, (Kennedy, 2007: 229-234). Todos ellos, como ya se ha dicho, estaban obligados a proporcionar tropas al Shahansha siempre que éste se lo reclamase y a menudo eran ellos mismos los que se ponían al frente de sus tropas. En efecto, tanto los príncipes lahmíes, el más famoso de los cuales sería al-Mundir (el "Alamundaro" de Procopio), como los nobles armenios, los príncipes albaneses y los reyes de Iberia comandaban sus propias tropas cuando éstas eran reclamadas por el rey de Persia. Así, por citar dos ejemplos, el rey de Iberia fue capturado por Heraclio en la batalla de Nínive cuando se hallaba peleando con sus hombres junto al ejército persa (Teófanes: 6118, 319), y era el propio príncipe Juansher de Albania el que mandaba los 3.000 albaneses caucásicos que pelearon junto a los persas en Qadesiya, Ctesifonte y Nehavend (Moisés Daxurangi: 2.18, 110-113).

¿A qué número podían ascender estas fuerzas auxiliares proporcionadas por los príncipes y jefes vasallos del Shahansha? Pues en nuestra opinión, ese número no debió de ser excesivamente alto, sobre todo si se lo compara con el del ejército regular del Rey de reyes. En cualquier caso y pese a que en los últimos años del imperio se advierte un incremento del número y de la importancia de esta clase de fuerzas dentro del ejército persa, el número total de sus efectivos no debió de superar los 30.000 hombres. Algunos eruditos han creído ver en esta creciente importancia de los destacamentos aportados por los pueblos vasallos del imperio, una suerte de barbarización del ejército persa similar a la que se cree encontrar en el ejército bizantino del mismo periodo. No estamos de acuerdo, pues aunque es cierto que se advierte claramente una cierta predilección por estas tropas a partir del reinado de Cosroes I, el grueso de los ejércitos persas siguió estando formado por súbditos directos del rey persa y su espina dorsal siempre estuvo constituido por los Savaran, la caballería aportada por la nobleza persa (Rubin 1995: 284-285).

Lo creemos así porque el número de estos contingentes auxiliares en los distintos episodios bélicos que se produjeron entre 530 y 642, es siempre muy modesto según las fuentes: 2.000 caballeros armenios conducidos por los nobles armenios Varazsapuh Arcruni, Sargis Tayechi, Artawazd, Vstam y Hmayeak Apahuni, Manuel, señor de los Apahunis, Vram, señor de los Golthiens, Sargis Dimakhsean y Sargis Trpatun, que fueron convocados en 618 por el príncipe armenio Smbat Bagratuni para que lucharan bajo las banderas de Persia contra los heftalitas y los turcos occidentales (Sebeos: 48); otros 4.000 caballeros armenios batallando por Persia bajo las banderas de los príncipes armenios Musel Mamikonien y Gregorio de Siunie (Sebeos: 99); 3.000 jinetes albaneses militando, bajo la jefatura de su príncipe Juanser, en el ejército de Yezdiguerd III que intentó frenar a los árabes entre 635 y 642 (Moisés Dasxurangi: lib. 2, cap. 18, pp. 110-113); y quizás 15.000 árabes lahmíes conducidos por su rey al-Mundir para pelear en 531 junto a los persas en la batalla de Calínico, pues este es el número máximo de lahmíes que pudieron participar en esta batalla. Algo que se deduce con claridad porque los persas dividieron su línea de batalla en dos alas iguales: una constituida por 15.000 savaran persas y otra formada por los lahmíes. (Procopio, Guerra persa: I, 17-18, 104-118), siendo este último además el mayor contingente de guerreros de este tipo de todos los que se mencionan participando en un ejército persa a lo largo de todo este periodo. 
Por lo tanto, todo parece indicar que estas tropas auxiliares proporcionadas por los príncipes y jefes locales vasallos del Rey de Reyes no eran excesivamente numerosas, y dado que nunca se vio más de 4.000 armenios, 3.000 albaneses o 15.000 árabes, militando en un ejército persa, no es arriesgado - en nuestra opinión - suponer que el número total de estas tropas no debía de superar los 30.000 hombres. Un ejemplo claro de esto lo tenemos en la batalla de Qadesiya. Sebeos dice que los persas reunieron a 80.000 hombres (Sebeos: 97-99); también por Moisés Dasxurangi (Moisés Dasxurangi 2.18, 110-113) sabemos que en ese mismo ejército de 80.000 hombres sólo había 4.000 armenios y 3.000 albaneses, ni una décima parte del total. Puede que otros príncipes locales proporcionaran también contingentes a este ejército persa, pero, dado que en este periodo eran los armenios y los albaneses las principales fuentes de guerreros no persas con los que contaba el rey de reyes, es fácil suponer que la inmensa mayoría de los 80.000 hombres que combatieron en Qadesiya eran persas.

No obstante estas tropas auxiliares eran muy valoradas por los persas, siendo especialmente célebres y afamadas las tropas de caballería pesada proporcionadas por la nobleza de la Perso-Armenia y por los príncipes de los albaneses caucásicos. También eran famosas las compañías de caballería ligera que los árabes lahmíes y diversos grupos de turcos y heftalitas asentados en el Eranshar proporcionaban al ejército persa y que le eran a éste imprescindibles como tropas custodias de las largas y desérticas fronteras arábigas y turanias del Eranshar, así como tropas de descubierta, exploración y hostigamiento. Por último, eran también célebres los infantes y jinetes que el rey de Iberia enviaba a servir bajo las banderas del Shahansha.

En cuanto a los mercenarios (que algunos autores suelen confundir con las tropas enviadas por los príncipes vasallos del imperio) nunca fueron especialmente numerosos y sólo sabemos de pequeños contingentes de turcos sirviendo en las fronteras de Gurgan y de algunos destacamentos de alanos patrullando las fronteras más norteñas de Iberia y Albania.

Así que, si sumamos al ejército permanente persa de fines del siglo VI los contingentes proporcionados por sus vasallos, la cifra total de fuerzas realmente equipadas y adiestradas para hacer frente a una situación bélica rondaría los 150.000 hombres, cifra similar a la de los soldados que militaban en los ejércitos de campaña de Justiniano I y de sus inmediatos sucesores.

Pero como se recordará, Persia aún podía disponer — si la situación lo requería - con una tercera fuente de efectivos: la procedente de las levas masivas y forzosas que se podían realizar entre su campesinado y de las que se extraía el grueso de su infantería ligera. ¿Cuántos hombres podían llegar a proporcionar estas levas?

Es difícil establecer su número, pero las fuentes permiten realizar una aproximación que sin duda no debe de estar muy lejos de la realidad. Así, si volvemos sobre la Crónica de 1234, se recordará que informaba que de los 183.000 hombres que Cosroes I plantó ante los muros de Dara en 573, 120.000 eran «campesinos». Estos «campesinos» no eran otros que los soldados que el Rey de Reyes reclutaba mediante levas forzosas y sin derecho a sueldo, entre el sufrido campesinado persa. Estos soldados, armados con un gran escudo de mimbre, una lanza y a veces con una honda o con una espada (es decir, un armamento similar al que más de mil años atrás portaban los infantes persas que participaron en la invasión de Grecia durante las Guerras médicas) no tenían preparación militar alguna y recibían el nombre de paighan (Farrokh, 2005: 23). Es muy posible que los 120.000 paighan citados por la Crónica de 1234 supusieran el grueso de los efectivos que Persia podía llegar a reclutar mediante estas levas forzosas. En cualquier caso, los paighan sólo podían ser usados por tiempo limitado pues, de otro modo, Persia vería perjudicada su base productiva al privar a su agricultura de tantos brazos; además estos soldados no recibían, ni ellos ni sus familias, ningún ingreso a cambio de su servicio militar.

Teniendo en cuenta lo anterior es fácil colegir que Persia no podía recurrir en exceso, ni por largos periodos de tiempo, a este tipo de levas sin agotarse. Tal situación de agotamiento 
llegó durante la larga guerra romano-persa del 603-628, cuando las prolongadas campañas en la Romania, la necesidad de guarnecer y ocupar las provincias conquistadas, y las cuantiosas pérdidas, obligaron a Cosroes II a llevar a cabo una sucesión de levas en las que el número de campesinos reclamados y perdidos fue tan elevado que en 626 , agotados los recursos que podía aportar para tal fin el campesinado, se vio obligado a efectuar una leva extraordinaria entre los artesanos, esclavos y comerciantes persas, casta que hasta ese momento estaba excluida por completo del servicio militar (Teófanes: 6117, 315). Es muy posible que esta continua sucesión de levas efectuadas entre el campesinado y la extensión de las mismas a artesanos, comerciantes y demás clases urbanas, hasta entonces libres de esta carga, fuese una de las causas del descontento general que precipitó la caída de Cosroes II. Así que el número de hombres que Persia podía extraer de sus levas forzosas de campesinos estaba limitado a que éstos fuesen usados durante un corto periodo y a que el número de los reclutados no gravitase en exceso sobre su economía. Por todo ello y como se ha dicho ya, los 120.000 paighan mencionados en la Crónica de 1234 debían de estar muy cerca del tope que tales efectivos podía proporcionar al soberano sasánida. En cualquier caso, en nuestra opinión y en el mejor de los posibles escenarios, Persia no podría poner en pie de guerra a más de 150.000 paighan.

Así que, recapitulando, podemos concluir que Persia, y sólo en momentos de gran necesidad y por un tiempo limitado, podría llegar a poner en pie de guerra un total de 300.000 hombres: 70.000 savaran, que formaban la élite de su ejército y el grueso de su caballería pesada; 50.000 infantes de línea, 30.000 auxiliares que aportaban a Persia la indispensable caballería ligera, y completaban las filas de su caballería pesada y de su infantería, y 150.000 paighan o infantes ligeros. Pero dado que, como ya se ha advertido, estos últimos, los paighan, que representaban la mitad del total, no podían ser mantenidos en servicio por mucho tiempo, la aparente superioridad numérica que Persia tenía sobre la Romania era más un espejismo que una realidad.

\section{BIBLIOGRAFÍA}

Agapios (1971): Kitab al- 'Unvan. Histoire universelle écrite par Agapius (Mahboub) de Menbidj. Turnhout, Brepols.Trad. Vasiliev, A.

Agatías (2008): Agatías. Historias. Madrid, Gredos. Trad. Ortega Villaro.

Amiano Marcelino (2002): Amiano Marcelino. Historia. Madrid, Akal. Trad. Harto Trujillo, $\mathrm{M}^{\mathrm{a}} \mathrm{L}$.

Christensen, A. (1944): L'Iran sous les Sassanides. Copenhague, E. Munksgaard.

Crónica de 1234 (1997): "Extract from the Chronicle of 1234", The Seventh Century in the West-Syrian Chronicles. Liverpool, Trans. Palmer, A.

Farrokh, K. (2005): Sassanian Elite Cavalry AD 224-642. Nueva York, Osprey Publishing.

Farrokh, K. (2007): Shadows in the Desert: Ancient Persia at War. Nueva York, Osprey Publishing.

Firdusi (1878): Le Livre des Rois par Abou'lkasim Firdousi, vol. V-VII. París, Imprimerie Nationale. Mohl, J.

Greatex, G. y Lieu, S. N. C. (2002): The Roman Eastern Frontier and the Persian Wars. Part II 363630. A narrative source book. Londres-Nueva York, Routledge.

Historia Nestoriana: Trad. Scheer, E. (1971): "Histoire Nestorienne (Chronique de Seert). Second partie (1)", Patrologia Orientali.Turnhout, t. VIII, fasc. 2, XXXVI, 195 (103).

Howard-Jonhson, J. (1995): "The Two Great Powers in Late Antiquity: a Comparison", Cameron, A. (ed), The byzantine and early Islamic near east. Nueva Jersey, vol. III: States, resourses and armies, 157-226.

Kennedy, H. (2007): Las grandes conquistas árabes. Barcelona, Crítica.

Mas'udi: Révisée et corrigée par Pellat, Ch. (1965): Mas'udi. Les prairies d'or. 5 vols. Paris: Société Asiatique.

Miguel el Sirio: Trad. Chabot, J.B. (1963): Chronique du Michel le Syrien Patriarche Jacobite d'Antioche, 4 vols. Bruselas, Culture et Civilisation. 
Moisés Daxurangi (1961): The History of Caucasian Albanians by Movses Dasxuranci. Londres, Oriental Series. Trans. Dowsett, C.J.F.

Patriarca Nicéforo (2013): Patriarca Nicéforo. Historia Breve. Granada (en presa). Trad. Motos Guirao, E.

Procopio, Guerra Persa (2000): Procopio, Historia de las Guerras. Libros I-II: Guerra persa. Madrid, Gredos. Trad. García Romero, F. A.

Rubin Z. (1995): “The Reforms of Khusro Anushirwan”, Cameron, A. (ed.), The Byzantine and early Islamic Near East, vol. III, 227-297.

Sebeos: (1904): Histoire d'Heraclius par l'êveque Sébéos, traduit de l'arménien et annoté. Paris, Imprimerie Nationale. Trad. Macler, F.

al-Tabari: Trans. Cliffort E. Bosworth (1999): The History of al-Tabari, vol. 5: The Sasanids, the Byzantines, the Lakhmids and Yemen. New York, State University of New York.

Teófanes: Trans. Mango C. y Scott, R. (1997): The Chronicle of Theophanes. Byzantine and Near East History AD 284-813. Oxford, Clarendon Press.

Teofilacto Simocata: Trans. Whitby, M. - Whitby, M. (1988): The History of Theophylact Simocatta. Oxford, Clarendon Press.

Recibido: $15 / 07 / 14$

Aceptado: 24/05/15 
